This is the peer reviewed version of the following article: O'Dwyer, E., Lyons, E. \& Cohrs, J.C. (2016) How Irish citizens negotiate foreign policy: A social representations approach to neutrality. Political Psychology, 37(2), pp. 165-181, which has been published in final form at https://doi.org/10.1111/pops.12242. This article may be used for non-commercial purposes in accordance with Wiley Terms and Conditions for Use of Self-Archived Versions. 
Running head: How Irish citizens negotiate foreign policy

How Irish citizens negotiate foreign policy: A social representations approach to neutrality

Keywords: social representations, identity, foreign policy, neutrality

Emma O’Dwyer, Evanthia Lyons, and J. Christopher Cohrs

${ }^{1}$ Kingston University, London

${ }^{2}$ Kingston University, London

${ }^{3}$ Jacobs University, Bremen

Word count (exc. figures/tables): 8884

*Requests for reprints should be addressed to Emma O'Dwyer, Kingston University, London, UK (e-mail: e.odwyer@kingston.ac.uk). 
The present study investigates the relationship between the foreign policy orientation of Irish neutrality and national identity using a social representations approach (Elcheroth, Doise \& Reicher, 2011; Moscovici, 1961/76). In four focus groups conducted in the Republic of Ireland, 22 participants discussed vignettes in which hypothetical conflicts were described. The findings pointed towards the dynamic relationship between neutrality and Irish national identity, and more generally to the importance of macro-political phenomena for identity construction. The process of categorisation was key to participants' decision-making regarding the hypothetical conflicts; the decision to support or oppose the Irish state's involvement in the conflicts frequently revolved around a reconsideration of the boundaries of the in-group. Furthermore, social representations were laden with the possibility of social change; the construction of neutrality as morally ambivalent, motivated by pragmatism rather than principles, opened up a space for younger participants to resist dominant, pragmatic interpretations of the policy and offer alternatives. Theoretical and empirical implications of the findings are discussed. Taken together, the findings demonstrate the critical potential of extending a social representations approach to issues of political psychological significance. 
The way in which people make sense of, and relate to foreign policy, has been the focus of much research within political psychology. A large body of work has focused on individual level determinants of foreign policy opinions, to name a few of the most prominent: ideology (e.g. Huddy, Feldman, \& Weber, 2007; Reifler, Scotto, \& Clarke, 2011), trust (Brewer \& Steenbergen, 2002), values (Bègue \& Apostolidis, 2000; Cohrs, Moschner, Maes, \& Kielmann, 2005) and socio-demographic markers such as gender (Conover \& Sapiro, 1994; Eichenberg, 2005) and ethnicity (Kam \& Kinder, 2007; Mueller, 1973; 1994) have all been explored as central to distinguishing the positions which people take towards specific foreign policy events (e.g. support or opposition to conflicts) and war, military and humanitarian intervention more generally. Other research has adopted an alternative, social representational approach (e.g. Orr, Sagi, \& Bar-On, 2000; Sarrica \& Contarello, 2004; Wagner, Valencia, \& Elejabarrieta, 1996), viewing individual and group positions towards foreign policy as part of the fabric of a broader constellation of images, values, category constructions, social practices, beliefs and attitudes. From this perspective, the question is less how individual variation in foreign policy opinion might best be explained, but rather how socially-located individuals participate, engage with and resist social representations which construe certain social practices, normative beliefs and category constructions as valid. While the former approach arguably views 'the context' of foreign policy opinion as a set of external factors limiting generalizability, for the latter it is the crucial material for rich analytical interrogation. This paper represents an attempt to advance a social representational approach to the investigation of political issues (Elcheroth, Reicher \& Doise, 2011) by tackling an intriguing phenomenon: the foreign policy orientation of neutrality in the specific context of the Republic of Ireland.

\section{The Politics of Social Representations}


Social representations theory (Moscovici, 1961/76) offers a theoretical framework for how people understand social objects, which may be remote or obscure, such as technical, scientific or political discourse. Social representation denotes both process and object; that is the stock of knowledge, images and beliefs about social objects as well as how these repositories of social knowledge are constructed and used in everyday life. Social representations occupy the 'in between' space (Jovchelovitch, 2007) between the individual and the social; it is in the relationships between these levels of analysis, in the mediated space between individuals, groups and the political and social context, that representations take shape.

The process of social representations is not consensual; rather social representations are underpinned by a "dialectic of cooperation and conflict" (Howarth, 2006, p. 71). They are dilemmatic - characterised by tensions, contradictions, arguments and counter-arguments (Billig, 1993). The phenomenon of cognitive polyphasia also foregrounds the issue of conflict in social representations; denoting the "plurality of representational fields, where differing, and at times conflicting, styles of thinking, meaning and practices, co-exist in the same individual, institution, group or community" (Renedo \& Jovchelovitch, 2007, p. 783).The concept of themata refers to the centrality of interdependent antinomies, for example self/other (Moloney, Williams \& Blair, 2012), to polyphasia in the process of social representation (Marková, 2003). In practice, this can mean that people draw upon oppositional representations in their construction of social objects (e.g., Figueiredo, Valentim, Licata, \& Doosje, 2013; Jovchelovitch \& Gervais, 1999; Renedo \& Jovchelovitch, 2007). For example, social representations of mental illness in India were found to be polyphasic, simultaneously drawing upon discourses of Western medicine and traditional Indian conceptions of mental illness (Wagner, Duveen, Verma, \& Themel, 2000). 
The social representational approach proposed by Elcheroth, Doise, and Reicher (2011) usefully extends the theoretical framework to incorporate a more fully-realised account of the relationship between identities and representations, the role of power, and the processes of social change. This approach foregrounds four key attributes of social representations: they are (1) shared knowledge, which importantly makes action a possibility; (2) meta-knowledge, in that what we believe others are thinking is just as significant as what we ourselves believe; (3) enacted communication, which may be written in social and institutional practices, spatial features etc.; and (4) world-making assumptions, that is they constitute and are constituted by social reality. Their approach rejects the false dichotomy between 'the psychological' and 'the political' spheres; representation is a fundamentally political process both "in terms of the bodies of knowledge we draw upon... and also in terms of how specific knowledge...both buttresses and is buttressed by whichever worldview is invoked" (p. 732).

In line with such a perspective, it is evident that social representational processes are fundamentally bound up with issues of power. Representations win out and become taken for granted at the expense of alternative representations, which may be associated with other, less dominant groups in society (Howarth, 2006). Political influence and control then concerns representational processes as much as overt domination. Power is banal, riven in social practices, institution and interpersonal communication, and crucially, it is a process in which individuals and groups possess agency. Agency may denote the capacity to resist stigmatising representations by engaging in identity-protective work (Howarth, 2002), through the process of anchoring (Duveen, 2001) or through cognitive polyphasia, which may take the form of ambivalence, or agreement in principle but disagreement in concrete examples (Castro, 2012). More broadly, agency may be considered as the potential of individual or group 
action, "to shape mutual expectations within a collective" and thus the actions of others (Elcheroth et al., 2011, p. 745).

The social representational approach also foregrounds the issue of identity, by emphasising the importance of social categories and their construction for representational work (Elcheroth et al., 2011). In this respect, it is consonant with previous work, which has drawn upon social identity theory to flesh out the individual, intragroup and intergroup consequences of social representation (e.g. Howarth, 2002; Klein \& Licata, 2003; Moloney \& Walker, 2007). To avoid reification and essentialism, identity should be treated as a social representation (Andreouli \& Chryssochoou, 2014), even if it may be a particularly distinctive one (Elcheroth et al., 2011). Moreover, identity is inextricably linked to action; the construction of social categories is strategic and future-oriented and is drawn upon by 'entrepreneurs of identity' in the pursuit of political objectives (Reicher \& Hopkins, 2001; 1996b; 1996a). One particular identity - national identity - has arguably been one of the most enduring and effective mobilisatory tool for elites; conceptualisations of this difficult phenomenon will be briefly discussed below.

\section{National Identity}

As mentioned above, following other work, national identity is conceptualised here as a social representation, which holds its enduring significance due to the development of the nation-state in the mid nineteenth century as the most important actor in international affairs (Gellner, 1997). By that, it follows that it comprises both content and process. Its content dimension encompasses the multitude of narratives, symbols, representations of out-groups, values and practices which gives the national group a sense of who it is, both in terms of essential characteristics, and also on a relative dimension, as it pertains to its position towards other groups. Following social identity theory (Tajfel \& Turner, 1979), the process of national identification or affiliation may carry negative consequences for how people interact 
with out-group members. In practice, it connotes the ways in which national identity, by now an unseen and taken for granted facet of our social world, is continually reproduced in everyday interaction (e.g., Billig, 1995; Condor, 2000). As with all social representations, national identities are sites of consensus and argument; what it means to be a member of a national group will vary depending on, for example, subordinate identification and identity motives (Breakwell, 1986). Moreover, as highlighted above, identities advance and sustain particular projects; the meaning of national identities is context-dependent (Klein \& Licata, 2003) and may be crafted by elites to align with political aims.

\section{Irish Neutrality: An Ambiguous Stance}

In a world characterised to an ever-increasing extent by global co-operation and integration, the foreign policy orientation of neutrality fulfils an indeterminate role. Tracing its development as a normative legal principle to the Hague Conventions of 1907, it is formally defined as

A deliberate, conscious policy of impartial abstention from a war or armed conflict with concomitant rights and duties, together with an intention to resist violations of those rights and duties by armed resistance if necessary.

(Salmon, 1989, p. 27)

The policy has been part of the political and cultural landscape of the Republic of Ireland arguably since the start of the nineteenth century (Fanning, 1982), but took on a greater significance on Ireland's decision to remain neutral during World War II. Despite Ireland's membership of the European Union in 1973 and the increasing push towards policy integration between the member states, neutrality remains a policy of which Irish citizens are broadly supportive (Keatinge, 1985; Gilland, 2001). Nevertheless, this integrative imperative is evident in political discourse, which has reframed Irish neutrality as 'military neutrality', merely denoting the state's stance apart from formal military alignments, such as NATO (O'Regan, 2010). Citizen resistance to this qualified repositioning of neutrality was 
evident in debates around European integration, for example the Lisbon Treaty referenda of 2008 and 2009, in which the loss of neutrality was a significant concern for Irish citizens (Sinnott, Elkink, O'Rourke, \& McBride, 2009; Sinnott \& Elkink, 2010).

National identity has been suggested to play a role in maintaining public support for neutrality (e.g., Devine, 2008; Fanning, 1982; Keatinge, 1978). Devine (2008) found that strength of Irish national identity positively predicted support for neutrality. She stated that "the concept of Irish neutrality as understood by the Irish people is a reflection of their values and a projection of their national identity in international affairs" (p. 473). The policy has been viewed as fulfilling the need to assert Irish sovereignty or independence, especially useful to the citizens of a newly-independent nation (Devine, 2008; Keatinge, 1978; Jesse, 2007; Jesse, 2006; Goetschel, 1999; Fanning, 1982). Keatinge (1978) posited that support for neutrality (especially during World War II) could be explained in part by "the psychological need for a dramatic manifestation of independence" (p. 78).

However, Irish neutrality during World War II carries negative connotations, especially in light of the Holocaust. The decision taken by Éamon de Valera, the Irish war-time Taoiseach (Prime Minister), to extend the Irish people's sympathies to Germany on the occasion of Hitler's death, seems especially morally questionable. Neutrality has been associated with other negative traits, such as "emotional self-satisfaction" and "smugness" (Fanning, 1982, p. 33). More recently, junior government Minister, Lucinda Creighton, related the policy to narcissism:

We have developed this perception of ourselves that to be neutral and to not engage in any sort of common defence is a badge of honour... That position on neutrality is quite narcissistic: we do not have to worry about its consequences, and we can parade it around the world, go to the United Nations and tell everyone how wonderful we are. But that has become part of Irish identity and it will be very hard to change.

(Mac Cormaic, 2013) 
These competing narratives of neutrality, as a buffer against increasing European integration and thus as a symbol of sovereignty, or as an ostrich-like and morally dubious predisposition of Irish citizens, almost akin to a character deficit, point towards the ambivalent and sometimes contradictory position which the policy occupies. Furthermore, it suggests that the relationship of Irish neutrality to national identity is similarly ambiguous.

\section{The Present Study}

To illustrate the potential of adopting a social representations approach to the investigation of political phenomena, Irish neutrality was investigated as a case study. Of central importance was the way in which (1) social representations of neutrality were linked to Irish national identity; (2) meta-representational content served to close down or open up possibilities for action and resistance; and (3) macro-political discourse impacted on individual and group-level identity negotiations. To examine these issues, a focus group study was conducted, wherein participants read and discussed hypothetical conflict events, which each proposed different courses of action for the Irish government or military.

\section{Method}

\section{Participants}

Twenty two participants (12 male and 10 female) took part in four focus groups in a small town (population approximately 8,000) in the Republic of Ireland. Previous research has suggested the importance of age (Wagner et al., 1999) as a variable for organising positions towards social representations; therefore participants of varying ages were included in the sample. Thus, two of the focus groups were made up of participants aged 50-60 years while the remaining two's participants were aged 18-25 years. For each of the participant age groups, one focus group comprised of those who had completed some third-level education while the other comprised of those who had not. This was intended to capture another 
variable posited to play a role in organising positions towards neutrality - class, which predicted rejection of the Lisbon Treaty (Sinnott, Elkink, O'Rourke, \& McBride, 2009), during the debate of which neutrality was an important issue. Supported by the medium-tostrong correlation found between educational achievement and socioeconomic status (Sirin, 2005) level of educational attainment was taken as a proxy for socioeconomic status. ${ }^{1}$

\section{Procedure}

Participants were solicited by contact with a number of social, political and educational groups in the locality, as well as advertisement in the local media and use of the 'snowball' sampling technique. The focus groups took place in the town library, lasted between 50 and 70 minutes and were moderated by the first author. The discussions, which were audio-taped, centred around three vignettes, which described hypothetical conflict situations in which it was proposed that Ireland would become involved (see Appendix). Following the description of the conflict and proposed intervention, the vignette detailed some of the arguments in support of or against the proposed action, which formed the basis of the ensuing discussions. The focus group schedule contained questions that tapped (1) the emotional responses that participants had to the scenario, (2) the Irish state's predicted and advised course of action, (3) the factors relevant to their decision making and (4) the perceived advantages and disadvantages associated with Ireland's actions. However, participants were free to (and often did) bring up other issues which they felt relevant to the discussion.

\section{Analysis}

The audio files were transcribed and analysed by the first author using thematic analysis (Braun \& Clarke, 2006). The transcripts were first read numerous times in order to

\footnotetext{
${ }^{1}$ In the excerpts which follow, 18-25 and 50-60 refer to the participant age groups, and H-Ed and L-Ed refer to participants who had completed some third level education, and those who had not, respectively. No differences between participants in terms of educational achievement were found.
} 
become familiar with the data. Initial descriptive codes (Level 1) were developed, the content of which basically mapped onto questions contained in the focus group schedule. Then, codes of similar meaning were grouped into broader themes and labelled (Level 2). These themes were reviewed to ensure they were sufficiently distinct and meaningful. The relationships between these themes were then assessed and described, and finally, were grouped again to denote broader narratives or ways of constructing the relationship between neutrality and national identity (Level 3). The meaning of each of these superordinate themes, as well as their relationship to each other, was then described in a detailed analysis. The results of the coding process are displayed in Table 1.

\section{Findings}

The findings presented here reflect and draw upon the thematic structure displayed in Table 1. To facilitate the appreciation of the relationships between themes, however, their organisation does not follow the thematic structure in a linear fashion. Instead, three key findings will be described, fed by the themes of the analysis, which shed light on the relationship between Irish neutrality and national identity, and, more generally, speak to the argument for adopting a social representational approach in the investigation of political psychological issues (Elcheroth et al., 2011).

\section{The consequences of macro-level phenomena for identity}

Throughout the discussions, national identity was constructed as constantly informed by, and in conversation with, the global political system. Specifically, macro-political phenomena were linked to the identity negotiations of participants. Constructions of Ireland's membership of supranational organisations such as the European Union, and especially their perceived associated demands of reciprocity, fed into the theme of 'constraint versus agency' limiting or opening up possibilities for the practice of neutrality. Yet at the same time, these 
same state-level entanglements were constructed by participants as a source of identity; they were a means of 'projecting national identity'.

In relation to the theme of 'constraint versus agency', particular ways of constructing the relationship of the Irish state to international systems, actors and institutions, served to enable or constrain the practice of Irish neutrality. For example, decisions regarding involvement were not taken within a historical vacuum; the presence of a precedent for a proposed involvement served to justify further similar actions:

And all we're doing is allowing them to refuel in Shannon which they're doing all the time anyway, which doesn't affect our military neutrality irrespective of what people say or don't say.

(M, 50-60, L-Ed)

But Ireland does this anyway, so there's no reason to, really to refuse. Like why would Guinea be any different to the Lebanon?

(M, 18-25, H-Ed)

Constructions of the Irish state's pre-existing arrangements in terms of the USA's use of Shannon airport, and its involvement in UN peace-keeping activities, then have a reifying function - they normalise and legitimise similar on-going and future action. To put it differently, they are world-making assumptions (Elcheroth et al., 2011). Moreover, support for actions which 'fit' with the precedent can be seen to bolster the continuity of the in-group (Breakwell, 1993; 1986), as it both connects Irish citizens to their past and orients them towards their future.

The importance of macro-political phenomena for identity was also apparent in constructions of Irish involvement in United Nations peacekeeping activities, which were almost universally endorsed in the context of the hypothetical conflict events ('you can consider neutrality but kind of doing it for the UN really so it doesn't really matter' M, 18-25, L-Ed). Moreover, such involvement was constructed as 'projecting national identity', 
emphasising two self-definitions relevant to Irish national identity - its status as 'a peacekeeping nation' and, relatedly its 'moral authority'.

Par 3(M): We're seen as like a peace-keeping nation, different from a neutral nation, it seems like a different, we've been assigned a role of peacekeeping troops do you know what I mean. Like we're not in Iraq, we didn't send troops there...

Par 2(M): $\quad$ Not on the front-line.

I: $\quad$ Is that important to you, that Ireland is seen as a sort of peace-keeping nation? Playing the role of the peace-keeper, or do you think it's even true, that other countries see us that way?

Par 4(F): I think it's more of an advantage for, like I like to think of us as that, doesn't really bother me of how we're seen.

But we still have a voice. When the Irish speak, we're heard and listened to in the UN and I think we should probably, that's where our neutrality, and our neutrality enforces that.

In both excerpts it is clear how social representations are inseparable from the process of categorisation. The representation of the self-definition 'peace-keeping nation' is constructed as related to, but distinct from neutrality. The importance of meta-representations (Elcheroth et al., 2011) is apparent: this status is not one actively taken by the Irish people but conferred by others. Similarly the 'moral authority' of the Irish people is measured by its effect on others, by the extent to which other people engage with its content. These metarepresentations have the result of sustaining a positive Irish national identity, which is efficacious and distinctive and can 'punch above its weight' (M, 50-60, L-Ed).

The absence of a boundary between 'the political' and 'the personal' was also evident in constructions of the Irish army. Perhaps surprisingly, the Irish army specifically seemed to be a source of positive affect due to their perceived competence and ability to make a unique contribution in combat. 
I have one thing to say, any country that Irish troops have been involved in, the past fifty years, you know, a lot of people there, you know Ireland's got a lot of respect. You know Ireland's looked on favourably you know by the majority.

(M, 50-60, H-Ed)

Some of the best militia in the world are Irish, some of the best reconnaissance guys, they're Irish.

(M, 18-25, H-Ed)

Constructions of the army clearly work to emphasise the efficacy, self-esteem and distinctiveness of Irish national identity (Breakwell, 1986). The source of this positive national identity is also related to meta-representational processes. 'Respect' from 'the majority' takes precedence over personal sentiment. In this way, the realisation that most others are of the same opinion works to maintain the status quo, which in this case is to justify the continued involvement of the Irish army in peace-keeping missions. In this sense, it may be said that meta-representations solidify to lend specific political opinions and their associated actions a normative force.

\section{Constructing the in-group: A pragmatic and strategic collaboration}

Macro-political phenomena also impacted on constructions of the in-group, that is global issues extrinsic to Irish national identity influenced how it was represented. Representations of the in-group fed into the theme of 'constraint versus agency'; the construction of actors involved in the conflict scenarios as inside or outside of the in-group underpinned justifications for or against Irish involvement, but more importantly often lent such involvement an inevitable quality. For example, participants frequently spoke about 'natural' pre-existing alliances between Ireland and countries such as the USA and Britain, which were based on a common history or values.

I: $\quad$ But am do you think Ireland would actually get involved in this then. Par 4(M): Yes.

I: $\quad$ You think they would.

Par 2(F): Yeah. 
Par 5(M): Because of Uncle Sam.

Par 3(M): I'm not sure it would.

Par 4(M): I don't know, even the question is irrelevant whether it's Uncle Sam or Ho Chi Minh over in China, the fact that we are more aligned with the west and we're actually, we're more American than European so I think we'd have absolutely no problem, our government would say no problem.

(50-60, L-Ed)

Yeah but we must go back, if you're going back that far, talking about the Russians, and I just want to make this, when Irish people, the only door they had open to them in the late eighteen hundreds, when we were dying with the famine was America. You can go out to the states and the majority of people have some connection to Ireland. So do we neglect them as well, and bring in Russians?

(F, 50-60, H-Ed)

The argument for involvement is underpinned here by emphasising the commonality between American and Irish national identity ('we're more American than European'), which is rooted in collective memories of the Irish famine and the diasporic link between the two countries. The use of these justifications works to close off the possibility of staying outside the conflict.

There was a particular sensitivity to two characteristics of the actors involved in the hypothetical conflicts - threat and closeness - which either motivated or constrained Irish involvement. Threat was related in particular to perceptions of terrorism and of China; in general, greater threat to Ireland (economic or security) was discursively connected to arguments against involvement. As in the below exchange, closeness was frequently unrelated to geography:

Par 4(M): Yeah, the Colombans (Irish Catholic missionary priests) are there, but it's sort of skewed, the Philippines isn't just this distant exotic country.

Par 1(F): No, it's not.

Par 5(F): There's Filipinos, I guess Nenagh (local hospital town), in the hospitals, every hospital. . .

Par 5(F): Oh, they are.

Par 4(M): The nursing homes, better again. 
Par 1(F): Yeah. The mother of the Rose of Tralee! (a famous Irish beauty pageant) (Laughing)

She is, yeah.

Par 4(M): The mother is a Filipino!

I: $\quad$ Oh yeah, really?

Par 1(F): Yeah.

Par 2(F): They can use Shannon. We have to look after our own!

(50-60, H-Ed)

In this exchange, the decision to support Irish involvement in a conflict in which the Philippines has been invaded by China, is made through a process whereby the limits of the national in-group are considered and extended ('we have to look after our own!'). Migration is the implicit driver of this reconfiguration of the Irish national in-group; the widespread employment of Filipino citizens in the Irish healthcare service has facilitated their integration into, and recognition in Irish society. Consequently, the decision to extend Irish assistance in this conflict is clear-cut.

The analysis shows that the representation of Irish national identity is a pragmatic and collaborative process, which has consequences for action. This interpretation is consonant with the view that identity must be considered as a specific social representation (Andreouli \& Chryssochoou, 2014; Elcheroth et al., 2011). It is context-dependent; as in the above excerpts characteristics of the global political system (e.g., migration, the Irish famine) bolster particular representations of the in-group and extend its boundaries. Moreover, social representations of identity are strategic; they are used creatively in the pursuit of political projects (Reicher \& Hopkins, 2001; 1996b; 1996a), in this case to support the argument for Irish involvement in conflict or to support the status quo in the domain of Irish foreign policy.

\section{Polyphasia, ambivalence and resistance}


The analysis suggested that social representations of Irish neutrality were polyphasic, in that they were underpinned by context-dependent and interdependent themata (Marková, 2003; Moloney, Williams, \& Blair, 2012), namely 'universal/conditional acceptance', 'pragmatism/principles' and 'self-interest/global responsibility'. Polyphasic representations gave rise to ambiguity and ambivalence, which, for younger participants, offered the discursive possibility of resistance to dominant representations.

Participants located themselves on a continuum between 'universal' and 'conditional' acceptance of neutrality in their discussions of the hypothetical conflict situations. Chiefly, participants achieved this by referencing economic considerations and the distinction between pragmatism and principles in foreign policy decision making. Economic arguments were linked by participants variously to 'universal' acceptance of neutrality - justifying the decision not to get involved - and to 'conditional' support for the policy - by justifying involvement based on the economic benefits which such a course of action would bring.

Par 4(M): Well it's always going to keep people in work as well.

Par 2(M): Yeah.

Par 1(M): True.

Par 4(M): Keep them in jobs.

Par 2(M): The more African dictators we have the better like.

Par 2(M): But it shouldn't be like, I know other countries need help to sort out their problems but why does it have to come, we're such a small country. Like we're like how many times the size of America, Ireland in American you know, we don't have enough, we can't, we can't possibly go in and do something like that. We shouldn't be the ones helping them out, we don't have the money for it, we can't afford it, we don't have the money for it. We said we're neutral, we're a peace-keeping country, no I don't think it's right.

Par 3(M): No country can afford it. I mean if it came down to it, every country in the world would prefer not to be sending troops anyway. I think the sense of responsibility of a peace-keeping country kind of outweighs the... 
In the first exchange, the decision to base the decision for involvement on economic factors, specifically in terms of employment benefit, seems consensual. War is a means to an end, the end being a positive economic outcome for Ireland ('The more African dictators we have the better'). In the second exchange, economic discourse is used to strengthen the argument against involvement. Importantly, this line of thinking is problematized and resisted by drawing on the thema of self-interest/global responsibility. In this sense, participants frequently drew upon but also resisted the use of pragmatic discourse to justify the decision of whether Ireland should become involved in the conflict events.

Participants were cognisant of the often limited nature of neutrality in practice, its ambiguous meaning and pragmatic treatment by political elites ('like they seem to pick and choose what countries they're neutral for', F, 18-25, H-Ed). This awareness, in addition to perceptions of neutrality as limited and based on pragmatism rather than principles, resulted in ambiguity and, for younger people, a sense of 'moral ambivalence'. This ambivalence, recognised as such, opened up a space for younger participants to resist dominant representations, to critique elite action and call for social change.

Older participants recognised the partial and limited nature of neutrality, but rationalised it with reference to Ireland's size and security needs:

Par 5(F): I think most people, while they agree with neutrality, know this goes on at Shannon, and it kind of sits a bit uncomfortably with them but they kind of turn a blind eye.

Par 2(F): They do.

Par 5(F): They do really, I mean, you know it just sits a bit uncomfortably with you. But then you forget about it.

Par 4(M): Sure we're too small guys.

Par 5(F): Yeah.

Par 1(F): That's what it is really.

Par 4(M): To take moral positions involving, I mean you can take moral positions but when it comes to sending troops out, your sons and daughters.

Par 1(F): That's it really. 
On the other hand, younger participants were generally unsatisfied with such a strategy. Conflicts which were constructed as 'extreme' in some way were especially problematic for younger participants when using neutrality to justify policy positions:

I mean there's been countless dictators like this you know, I mean fucking Gaddafi being the most recent one. We know what they're like ah you can't even argue, you can't even try to throw up a fickle argument like how this goes against Irish neutrality in the face of genocide, you know? It's, if the lads are able to do the job then let them go, let them help.

(M, 18-25, L-Ed)

Involvement is framed in terms of altruism but also the motive to preserve continuity (Breakwell, 1986; 1993) and against such arguments; the 'fickle' case for neutrality is diminished. Thus, for younger participants the ambivalence of neutrality was not something which could be explained away or dealt with and rather acted as a spur for change in neutrality's definition and practice - either towards 'full' neutrality and incorporating a more active involvement on the world stage ('I think if we're neutral we should stay neutral, one hundred per cent', F, 18-25, H-Ed), or rejecting the policy entirely in favour of greater international interdependence and co-operation in foreign policy. For younger people then, ambivalence in representations of neutrality denoted a starting point from which resistance was possible. It suggests awareness of the 'possibility of difference' (Glăveanu, 2009) and of the existence of alternative representations (Gillespie, 2008) to the hegemonic, pragmatic ones enacted in Irish foreign policy.

\section{Discussion}

The analysis suggests that Irish neutrality and national identity were dynamically related. Social representations of neutrality were functional, in that they sustained particular self-definitions which emphasised the continuity, distinctiveness and self-efficacy of the national group (e.g., 'a peace-keeping nation'). Our analysis then supports previous work 
which has emphasised the relationship between neutrality and national identity as a reason for its endurance and continued support among the Irish public (Keatinge, 1978; Devine, 2008). Moreover, as social representations, the respective contents of Irish neutrality and national identity were informed by macro-political phenomena, whether this referred to the Irish state's supranational memberships or particular ways of considering the state's relationship to, and place, in the world. Representations of neutrality were polyphasic; the analysis revealed the way in which this resulted in ambiguity and ambivalence, which created discursive possibilities for younger people to resist dominant or hegemonic representations.

Our findings showed that characteristics of the global political context impacted on the identity negotiations of participants. This was often evident in the way in which participants' considerations of broader political factors resulted in a reconsideration of the boundaries of the in-group. Given the increasingly globalised nature of the world, this was perhaps unsurprising. Constructions of the in-group were context-dependent, collaborative and pragmatic endeavours. In this sense, our findings echo previous work which has emphasised the necessity of considering identity as a social representation (Andreouli \& Chryssochoou, 2014), which is always action-orientated (Elcheroth et al., 2011; Reicher \& Hopkins, 2001). In addition to this, our findings underscore the fundamentally agentic process of identity construction; while participants grappled with larger geo-political factors, and indeed the legacy of past foreign policy decision-making, they demonstrated a clear capacity for creatively reshaping the content of national identity, and the membership of the in-group, within these parameters.

Participants' talk about the meaning and practice of neutrality reflected its dual position as a constrained and agentic policy, which suggested that representations of neutrality were polyphasic. Neutrality represented a way in which national identity could be expressed or enacted, but at the same time, restricted the options for the Irish state in terms of 
its foreign policy decision making. What is unclear is what the polyphasic quality of social representations of neutrality's consequences for identity was. In an increasingly globalised and integrated world, citizens are in a new and unfamiliar position as they negotiate their national group memberships and identities, as well as those associated with their supranational memberships. In this sense, polyphasic representations of neutrality could be interpreted as resistance to and acknowledgement of neoliberal globalized structures and institutions. Neutrality represents a container for the expression of Irish sovereignty within an integrated world system, but it also connotes a tacit acknowledge of the fundamental impossibility of neutrality within this altered system. This suggests that future research needs to attend to this disconnect between people's natural or lay conception of citizenship as referring to the nation state, and the external political and economic environment which signals the importance of global, connected and interdependent citizens. Thus, a more focused examination of the process in which citizens engage with multiple and sometimes conflictual identities is necessitated. While there is a growing social psychological literature on multiple identities, identity complexity and its antecedents and consequences (e.g., Roccas $\&$ Brewer, 2002), the question of how the globalized economic and political environment gives rise to syncretic identities might also be an equally valid and fruitful line of inquiry (Chiu \& Cheng, 2007). Like cultures (Holton, 2000), all identities are syncretic: they borrow from other identities, indigenize it and are then loth to acknowledge its origin. Such an assertion emphasises the necessity of construing identity as a dynamic and fluid construct, which is shaped as much by other identities and historical processes as the current sociopolitical context.

The analysis also speaks to the issues of power and resistance in social representations. Polyphasic representations of neutrality, which hinged on themata such as pragmatism/principles, universal/conditional acceptance and self-interest/global 
responsibility, had the effect of introducing ambiguity and ambivalence to the social representational field, which in turn opened up a space for younger participants to critique and resist what they perceived to be the partial and hypocritical practice of neutrality by elites. This finding suggests that polyphasic representations contain the potential for resistance, but a crucial catalyst for this process is the awareness of alternatives through a consideration of meta-representations (Elcheroth et al., 2011; Gillespie, 2008; Glăveanu, 2009). For younger participants, it was the recognition of neutrality as a pragmatic and qualified policy, attributed most clearly to elites, which prompted their critique. This in turn led to their promotion of an alternative neutrality, which would clearly either be active or passive, existent or non-existent; what was important was that it was unambiguous. In this sense, it may be read that one way in which polyphasic representations may be countered, and thus social change achieved, is by removing the inconsistencies, by rebalancing the emphasis of a relevant thema (e.g., universal or conditional acceptance).

This study benefited from the use of vignettes detailing hypothetical conflict events, which provoked the ambiguities and value tensions posited to be a central feature of social representations of neutrality. However, it may be considered questionable as to whether social representations of neutrality were in fact polyphasic, or whether this finding was merely the product of a researcher imposition. Two features of the discussions indicate the latter not to be the case. Firstly, relative to its appearance in the vignettes, neutrality was discussed disproportionately by participants. Secondly, participants did seem to have genuine difficulty negotiating the definitional ambiguity, moral complexity and incompatible actions associated with neutrality. Furthermore, imposing a polyphasic quality on social representations would in any case be impossible: social representations are not synonymous with independent variables which can be manipulated in an experimental setting. At the same time, the influence of the vignettes should not be precluded. It seems probable that the 
vignettes brought to the fore the pre-existing polyphasic quality of social representations of neutrality, which might otherwise have been less obvious.

As with all qualitative research, the question may be asked: to what extent are the reported findings valid or accurate? Concerns about validity, which can be seen as stemming from a post-positivist epistemology, seem incompatible with qualitative research. Instead, throughout the research process, reflexivity was used as "as a methodological tool to better represent, legitimize, or call into question their data" (Pillow, 2003; p. 186). Putting it somewhat differently, reflexive research has been defined as "characterised by ongoing selfcritique and self-appraisal" (Koch \& Harrington, 1998, p. 887). Strategies utilised by the researcher to engage in reflexive practice (e.g. writing memos, detailing perceptions of the focus group discussions) were not then used to bolster the scientific validity of the research but instead to enable additional insight and an understanding of the active role played by the researcher in the process.

Social representations are commonly accepted as comprising content and process how the object is represented by a population, but also the processes which shape what these social objects look like. In spite of the recognition of this point, most research on social representations tends to elaborate the content dimension of social representations only. A focus on content supposes the identification of elements (images, associations etc.) of a social representation. The 'structural' approach proposes that knowledge of the content is insufficient; in addition to identification of the constitutive elements of a social representation, it is necessary to understand the way in which they are interrelated (Abric, 2003). While also addressing the process of representation, in terms of content, this study focused on examining the constituent elements of the representation, rather than their interaction or structure. Further empirical work, utilising quantitative or experimental methods, is necessary to shed light on the internal organisation of the social representation. 
To conclude, this study has shown that representations of Irish neutrality are polyphasic and dynamically related to national identity. The analysis revealed the way in which national identity is constantly in conversation with the global political context; in the Irish case, supranational memberships and past foreign policy decisions feed into constructions of national identity, and crucially, have consequences for the way in which people orient themselves towards military or humanitarian intervention. This implies that future research should conceptualise identity as a social representation, which is negotiated with reference to macro-political phenomena, in addition to individual and interpersonal processes. Moreover, attitudes towards foreign policy, humanitarian and military intervention, rather than focusing on individual-level determinants, should be considered and examined empirically in light of these (social) processes. The analysis also emphasises the importance of attending to the process of categorisation in conjunction with representation, which is creative and agentic, and similarly, has consequences for political opinion and action. Resistance and social change were suggested to be linked to reactions to polyphasia and ambivalence, which for young Irish people, led to their consideration and rejection of, meta-representations of neutrality as compromised and qualified. Taken together, the findings of this study underscore the utility of extending a social representations approach (Elcheroth et al., 2011) to issues of political psychological significance. The case of Irish neutrality demonstrates the way in which 'the political' and 'the psychological' are inextricably linked and interdependent, and we argue that one of the key ways of facilitating the critical potential of political psychology is through a fuller appreciation of this premise. 


\section{Appendix}

\section{Vignette A}

A terrorist attack has occurred in the city-centre of Berlin, resulting in the death of over 100 people and countless injuries. A group of Islamist terrorists based in Pakistan have claimed responsibility for the attack. The member states of the European Union are now planning to send troops to Pakistan to locate those responsible and bring them to justice. The United Nations Security Council has not yet approved this mission. The Irish government is now debating whether to send troops along with the rest of the European Union. Those in favour of sending troops argue that we must help our European neighbours, and the threat of terrorism needs to be reduced in the world. On the other hand, people against Irish involvement in the mission have pointed out that we need to preserve our military neutrality. Those against the mission are also worried about Pakistan's nuclear capability and the threat to Irish national security.

\section{Vignette B}

Following a disputed presidential election result, a civil war has broken out in the westAfrican country of Guinea. The last president, who has been in power for over 20 years, has held onto power even though international observers say that he lost the election. Many protests have taken place in support of the actual winner but have been violently stopped by the president's own supporters. There are rumours of mass executions of those opposed to the president, but this cannot be verified as no journalists are permitted to enter the country. The Irish government is considering sending 2,000 peace-keeping troops to Guinea through the UN. Those in favour of sending troops argue that urgent action needs to be taken to prevent further loss of life and also that Ireland must help uphold democracy in the developing world. Those opposed to the action say we cannot afford it and there is a substantial risk to Irish 
soldiers on this mission. Also some people say that, because considerable force will be used on this mission, it an example of peace-enforcing rather than peace-keeping and so goes against Irish neutrality.

\section{Vignette $\mathbf{C}$}

Following a political dispute, the Philippines have been attacked by China. The country possesses large natural gas reserves in its territorial waters. It is withstanding bombings in its cities and towns and Filipino citizens have fled to the countryside. The USA and Britain are sending troops to help the Philippines defend itself. This action has been approved by the United Nations Security Council. The USA would like Ireland to allow them to use Shannon airport so that their aircraft can refuel on their way to the Philippines. Those against this action have pointed out that it is in breach of Ireland's policy of military neutrality and it could result in a risk to Irish national security. On the other hand, those in favour of the action argue that we need to help the smaller, mostly Christian, country defend itself and prevent further loss of life. 


\section{References}

Abric, J.-C. (Ed.) (2003). Méthodes d'étude des représentations sociales. Ramonville SaintAgne: Erès.

Andreouli, E. \& Chryssochoou, X. (2014). Social representations of national identity in culturally diverse societies. Sammut, G., Andreouli, E., Gaskell, G., \& Valsiner, J. (Eds.), Handbook of Social Representations. Cambridge: Cambridge University Press.

Bègue, L., \& Apostolidis, T. (2000). The 1999 Balkan war: Changes in ratings of values and prowar attitudes among French students. Psychological Reports, 86, 1127-1133. doi:10.2466/pr0.2000.86.3c.1127

Billig, M. (1995). Banal nationalism. London: Sage.

Billig, M. (1996). Arguing and thinking. Cambridge: Cambridge University Press.

Billig, M. (1993). Studying the thinking society: Social representations, rhetoric, and attitudes. In G. Breakwell, \& D. Canter (Eds.), Empirical approaches to social representations (pp. 39-62). Oxford: Clarendon.

Braun, V., \& Clarke, V. (2006). Using thematic analysis in psychology. Qualitative Research in Psychology, 3, 77-101. doi:10.1191/1478088706qp063oa

Breakwell, G. (1986). Coping with threatened identities. Methuen, London: New York.

Breakwell, G. (1993). Integrating paradigms, methodological implications. In G. Breakwell, \& D. Kanter (Eds.), Empirical approaches to social representations (pp. 180-199). Oxford: Clarendon Press.

Brewer, R., \& Steenbergen, M. (2002). All against all: How beliefs about human nature shape foreign policy opinions. Political Psychology, 23, 39-58. doi:10.1111/0162895X.00269 
Burris, V. (2008). From Vietnam to Iraq: Continuity and change in between-group differences in support for military action. Social Problems, 55, 443-479. doi:10.1525/sp.2008.55.4.443Castro, P. (2012), Legal innovation for social change: Exploring change and resistance to different types of sustainability laws. Political Psychology, 33, 105-121. doi: 10.1111/j.1467-9221.2011.00863.x

Chiu, C., \& Cheng, S. (2007). Toward a social psychology of culture and globalization: Some social cognitive consequences of activating two cultures simultaneously. Social and Personality Psychology Compass, 1, 84-100. doi:10.1111/j.1751-9004.2007.00017.x

Cohrs, J., Moschner, B., Maes, J., \& Kielmann, S. (2005). Personal values and attitudes towards war. Peace and Confict: Journal of Peace Psychology, 293312.doi:10.1207/s15327949pac1103_5

Condor, S. (2000). Pride and prejudice: Identity management in English people's talk about 'this country'. Discourse \& Society, 11(2), 175-205.doi:

\section{$10.1177 / 0957926500011002003$}

Devine, K. (2008). Stretching the IR theoretical spectrum on Irish neutrality: a critical social constructivist framework. International Political Science Review, 29, 461-488. doi:10.1177/0192512108095723

Duveen, G. (2001). Representations, identities, resistance. In K. Deaux \& G. Philogène (Eds.), Representations of the social: Bridging theoretical traditions (pp. 257-270). Oxford: Blackwell.

Eichenberg, R. (2005). Victory has many friends: \{U.S.\} public opinion and the use of military force, 1981-2005. International Security, 30, 140-177. doi:10.1162/0162288054894616 
Elcheroth, G., Doise, W. and Reicher, S. (2011). On the knowledge of politics and the politics of knowledge: How a social representations approach helps us rethink the subject of political psychology. Political Psychology, 32, 729-758. doi: $10.1111 / \mathrm{j} .1467-9221.2011 .00834 . x$

Fanning, R. (1982). Irish neutrality: An historical review. Irish Studies in International Affairs, 1, 27-38.

Figueiredo, A., Valentim, J. P., Licata, L., \& Doosje, B. (2013). The past and the present (re)visited: War veterans' representations of the Portuguese colonial war. In R. Cabecinhas, \& L. Abadia (Eds.), Narratives and social memory: Theoretical and methodological approaches (pp. 76-91). Braga, Portugal: University of Minho.

Gellner, E. (1997). Nationalism. London: Weidenfeld and Nicolson.

Gibson, S. (2011). Social psychology, war and peace: Towards a critical discursive peace psychology. Social and Personality Psychology Compass, 5, 239-250. doi:10.1111/j.1751-9004.2011.00348.x

Gilland, K. (2001). Neutrality and the international use of force. In P. Everts, \& P. Isernia (Eds.), Public opinion and the international use of force (pp. 141-162). London/New York: Routledge.

Gillespie, A. (2008). Social representations, alternative representations and semantic barriers. Journal for the Theory of Social Behaviour, 38 (4). 375-391. Doi: 10.1111/j.1468-5914.2008.00376.x

Glăveanu, V. (2009). What differences make a difference? A discussion of hegemony, resistance and representation. Papers on Social Representations, 18, 2.1-2.22.

Goetschel, L. (1999). Neutrality, a really dead concept? Cooperation and Conflict, 34, 115139. doi:10.1177/00108369921961807 
Holton, R. (2000). Globalization's cultural consequences. The Annals of the American Academy of Political and Social Science, 570, 140-152.

doi:10.1177/000271620057000111

Howarth, C. (2002). Identity in whose eyes? The role of representations in identity construction. Journal for the Theory of Social Behaviour, 32, 145-162. doi:10.1111/1468-5914.00181

Howarth, C. (2006). A social representation is not a quiet thing: Exploring the critical potential of social representations theory. British Journal of Social Psychology, 45, 65-86. doi:10.1348/014466605X43777

Huddy, L., Feldman, S., \& Weber, C. (2007). The political consequences of perceived threat and felt insecurity. Annals of the American Academy of Political and Social Science, 614, 131-153. doi:10.1177/0002716207305951

Jesse, N. (2006). Choosing to go it alone: Irish neutrality in theoretical and comparative perspective. International Political Science Review, 27, 7-28.

doi: $10.1177 / 0192512106058624$

Jesse, N. (2007). Contemporary Irish neutrality: Still a singular stance. New Hibernia Review, 11, 74-95. doi:10.1353/nhr.2007.0007

Jovchelovitch, S., \& Gervais, M. (1999). Social representations of health and illness: The case of the Chinese community in England. Journal of Community and Applied Social Psychology, 9, 247-260. doi: 10.1002/(SICI)1099-1298(199907/08)9:4<247::AIDCASP500>3.0.CO;2-E

Jovchelovitch, S. (2007). Knowledge in context: Representations, community and culture. New York: Routledge. 
Kam, C., \& Kinder, D. (2007). Terror and ethnocentrism: Foundations of American support for the war on terrorism. The Journal of Politics, 69, 320-338. doi:10.1111/j.14682508.2007.00534.X

Keatinge, P. (1978). A place among the nations: Issues of Irish foreign policy. Dublin: Institute of Public Administration.

Keatinge, P. (1985). Ireland's foreign relations in 1984. Irish Studies in International Affairs, 2, 163-179.

Klein, O., \& Licata, L. (2003). When group representations serve social change: The speeches of Patrice Lumumba during the Colonese decolonization. British Journal of Social Psychology, 42, 571-593. doi:10.1348/014466603322595284

Lyon, A., \& Malone, M. (2009). Was Woodrow Wilson right? Assessing American attitudes towards humanitarian intervention. Journal of Peace, Conflict and Development, 141.

Mac Cormaic, R. (2013, February 4). Irish attitudes to neutrality 'narcissistic'. Retrieved January 10, 2014, from The Irish Times: www.irishtimes.com

Marková, I. (2003). Dialogicality and social representations: The dynamics of the mind. Cambridge: Cambridge University Press.

Moloney, G., \& Walker, I. (2002). Talking about transplants: Social representations and the dialectical, dilemmatic nature of organ donation and transplantation. British Journal of Social Psychology, 41, 299-320. doi: 10.1348/014466602760060264

Moloney, G., Williams, J. \& Blair, D. (2012). Cognitive polyphasia, themata and blood donation: Between or within representation. Papers on Social Representations, 21, 4.1-4.12. 
Moscovici, S. (1961/76). Psychoanalysis: Its image and its public. Cambridge: Polity Press.

O' Regan, M. (2010). Political language as a flexible friend: Irish parliamentary debate on the Iraq War. Irish Political Studies, 25, 1-21. doi:10.1080/07907180903431913

Orr, E., Sagi, S., \& Bar-On, D. (2000). Social representations in use: Israeli and Palestinian high school students' collective coping and defense. Papers on Social Representations, 9, 1-20.

Reicher, S., \& Hopkins, N. (2001). Psychology and the end of history: A critique and a proposal for the psychology of social categorization. Political Psychology, 22, 383408. doi: 10.1111/0162-895X.00246

Reicher, S., \& Hopkins, N. (1996a). Self-category construction in political rhetoric: An analysis of Thatcher's and Kinnock's speeches concerning the British miners' strike (1984-5). European Journal of Social Psychology, 26, 353-

371.doi: 10.1002/(SICI)1099-0992(199605)26:3<353::AID-EJSP757>3.0.CO;2-O

Reicher, S., \& Hopkins, N. (1996b). Seeking influence through characterizing self-categories: An analysis of anti-abortionist rhetoric. British Journal of Social Psychology, 35, 297311.doi: 10.1111/j.2044-8309.1996.tb01099.x/full

Reifler, J., Scotto, T., \& Clarke, H. (2011). Foreign Policy Beliefs in Contemporary Britain: Structure and Relevance. International Studies Quarterly, 55, 245-266. doi:10.1111/j.1468-2478.2010.00643.x

Renedo, A., \& Jovchelovitch, S. (2007). Expert knowledge, cognitive polyphasia, and health: A study on social representations of homelessness among professionals working in the voluntary sector in London. Journal of Health Psychology, 12, 779-790.

Roccas, S., \& Brewer, M. (2002). Social identity complexity. Personality and Social Psychology Review, 6, 88-106. doi:10.1207/S15327957PSPR0602_01 
Salmon, T. C. (1989). Unneutral Ireland: An ambivalent and unique security policy. Oxford: Clarendon.

Sarrica, M., \& Contarello, A. (2004). Peace, war and conflict: Social representations shared by peace activists and non-activists. Journal of Peace Research, 41, 549-568. doi: $10.1177 / 0022343304045976$

Sears, D., \& Valentino, N. (1997). Politics matters: Political events as catalysts for preadult socialization. American Political Science Review, 91, 45-64.

Sinnott, R., \& Elkink, J. (2010). Attitudes and behaviour in the second referendum on the Treaty of Lisbon. Retrieved September 10, 2012, from Department of Foreign Affairs. Retrieved from http://www.dfa.ie/uploads/documents/EU\%20Division/attitudes\%20and\%20behaviou r\%20second\%20referendum2010.pdf

Sinnott, R., Elkink, J., O'Rourke, K., \& McBride, J. (2009). Attitudes and behaviour in the referendum on the Treaty of Lisbon: Report prepared for the Department of Foreign Affairs. Geary Institute, University College Dublin.

Sirin, S. (2005). Socioeconomic status and academic achievement: A meta-analytic review of research. Review of Educational Research, 75, 417-453. doi: $10.3102 / 00346543075003417$

Wagner, W., Duveen, G., Verma, J., \& Themel, M. (2000). 'I have some faith and at the same time I don’t believe' - Cognitive polyphasia and cultural change in India. Journal of Community and Applied Psychology, 10, 301-314. doi: 10.1002/10991298(200007/08)10:4<301::AID-CASP585>3.0.CO;2-V 
Wagner, W., Farr, R., Jovchelovitch, S., Lorenzo-Cioldi, F., Markova, I. D., \& Rose, D. (1999). Theory and method of social representations. Asian Journal of Social Psychology, 95-125. doi:10.1111/1467-839X.00028

Wagner, W., Valencia, J., \& Elejabarrieta, F. (1996). Relevance, discourse and the 'hot' stable core social representations: A structural analysis of word associations. British Journal of Social Psychology, 35, 331-351. doi: 10.1111/j.2044-8309.1996.tb01101.x 
Table 1 Description of level 1-3 codes generated in thematic analysis

\begin{tabular}{|c|c|c|}
\hline Codes (Level 1) & Sub-themes (Level 2) & Themes (Level 3) \\
\hline $\begin{array}{l}\text { - Importance of the United Nations } \\
\text { - Efficacy of public opinion on neutrality } \\
\text { - Consequences of alliances and memberships } \\
\text { - Irish political culture and systems } \\
\text { - Constructions of the Irish army } \\
\text { - } \text { Balance of power } \\
\text { - Closeness } \\
\text { - Threat } \\
\text { - Emotional response to conflict }\end{array}$ & $\begin{array}{l}\text { a. Socio-political } \\
\text { institutions and } \\
\text { actors } \\
\text { b. Interpretations of } \\
\text { conflict and events }\end{array}$ & $\begin{array}{l}\text { 1. Constraint versus Agency } \\
\text { ‘...yeah it's alright if ye French } \\
\text { lads go...but we still want to be } \\
\text { part of everything Europe has to } \\
\text { offer' }(50-60, \mathrm{H}-\mathrm{Ed})\end{array}$ \\
\hline $\begin{array}{l}\text { - The basis of foreign policy decision making } \\
\text { - Self-interest versus global responsibility }\end{array}$ & $\begin{array}{l}\text { a. Economic } \\
\text { considerations } \\
\text { b. Pragmatism versus } \\
\text { principles }\end{array}$ & $\begin{array}{l}\text { 2. Universal versus } \\
\text { Conditional Acceptance } \\
\text { 'Yeah, I'm not using ethics or } \\
\text { what's right or wrong. } \\
\text { Technically our military } \\
\text { neutrality has not been } \\
\text { affected'. (50-60, L-Ed) }\end{array}$ \\
\hline $\begin{array}{l}\text { - The limits of neutrality } \\
\text { - Perceived seriousness of conflict } \\
\text { - } \quad \text { 'Exceptional' events } \\
\text { - } \\
\text { - } \text { Ad-hoc practinitional and legal ambiguity of neutrality }\end{array}$ & $\begin{array}{l}\text { a. The limits of } \\
\text { neutrality } \\
\text { b. Qualified neutrality }\end{array}$ & $\begin{array}{l}\text { 3. Moral Ambivalence } \\
\text { '...when you have like a } \\
\text { dictator murdering his own } \\
\text { people, it's just a different } \\
\text { game altogether, you know?' } \\
\quad(18-25, \text { L-Ed) }\end{array}$ \\
\hline $\begin{array}{l}\text { - Positive affect associated with peace-keeping } \\
\text { - } \text { Efficacy and the Irish army } \\
\text { - Meta-representations of Irish involvement } \\
\text { - Distinctive Irish 'voice' in international } \\
\text { affairs } \\
\text { - Symbolic importance of leading Irish } \\
\text { - } \text { personalities } \\
\text { - 'Pumanitarian contribution } \\
\end{array}$ & $\begin{array}{l}\text { a. A peace-keeping } \\
\text { nation }\end{array}$ & $\begin{array}{l}\text { 4. Projecting National } \\
\text { Identity } \\
\text { 'we're seen as like a peace- } \\
\text { keeping nation' (18-25, H-Ed) }\end{array}$ \\
\hline
\end{tabular}

